\title{
National Agendas and the English Divide
}

\section{Priscilla S. Rogers}

University of Michigan. Ann Arbor

THE ABC CONTINUES TO EXPAND its role as an international organization, one committed to "fostering excellence in business communication scholarship, research, education, and practice" (ABC Mission Statement, 1992; Locker, 1998). The addition of new regions in 1996-Asia and the Pacific, Caribbean, Central and South America, Europe-has only accelerated the pace of international activities.

While as of February 1998 non-US members comprised only $16 \%$ of ABC's total membership, internationalism is evident on all fronts, including the composition of $\mathrm{ABC}$ committees and journal editorial boards; the roster of $\mathrm{ABC}$ award recipients, conference presentations, and journal publications; and the introduction of new communication vehicles that invite global networking, for example, $\mathrm{BCQ}$ on the Web. One ABC journal devoted an entire issue to international concerns in 1997 (The Joumal of Business Communication, July), and ABC members have contributed to other special international issues of the Journal of Business and Technical Communication (July, 1997) and Technical Communication Quarterly (Summer, 1998). Other recent ABC researchers' works we might cite include Hagen's “Teaching American Business Writing in Russia: Cross-Cultures/Cross-Purposes" (a reflective gem on teaching) and Andrews's Technical Communication in the Global Community, a new text written from an international perspective. At the 1997 ABC International Conference in Washington, $\mathrm{DC}$, some 60 sessions were dedicated to international/intercultural topics, a "Distinguished Member Award" was given to Hilkka 
Yli-Jokipii, ABC Vice President for Europe, and the "ABC Distinguished Publication on Business Communication" award went to Japanese scholar Naoki Kameda.

This burgeoning interest prompted me to ask several $\mathrm{ABC}$ colleagues to describe issues and priorities in business communication from their perspective, in their parts of the world. The six responses that follow may be considered brief reports from the field. The authors represent three of the ABC's four regions outside the US; a bibliography of sources from the fourth region (Caribbean/Central and South America), prepared by Leticia Rodriguez Talavera, is available at BCQ on the Web.

Several shared propositions about research in business communication emerge from these articles:

- Teaching and research go hand-in-hand.

- To enhance business practice, research must center on authentic texts.

- Research must be multidisciplinary.

- Cross-cultural communications and intercultural negotiations comprise important research areas.

- Language learning, linguistic analyses, and discourse patterns are central areas of investigation.

These propositions match those in other definitions of the discipline in, for example, The Journal of Business Communication (Locker, 1998); Business Communication Quarterly (June, 1996); and Management Communication Quarterly (August, 1996). That match suggests some consensus. The six articles in this Forum, however, also suggest issues that are highly significant in some international contexts but which have not been systematically discussed. These issues, I believe, merit our attention as they impact our work and growth as a global research community: One involves the connection between research and national agendas; the other involves our divided perspective on English.

\section{National Agendas}

Every author associates business communication research activities with the achievement of national goals and public service. This association is explicit, for example, in Nakasako's recounting of business communication's historical development in Japan, which he traces to 
the 1934 formation of The Japan Business English Association. This Association, Nakasako explains, was created in an effort "to promote more effective, efficient, productive, and safe ways to further Japan's export/import interests by presenting research related to trading transactions and by appraising the Japanese public of the theoretical and practical uses of Business English." Taking a regional perspective, Tan reports that "business communication research in Malaysia and Singapore emerged in part from a felt need to serve the dynamic economic growth in the Pacific Rim region." Charles and Yli-Jokipii tie their communication research efforts to participation in the European Union.

McLaren connects research in Australia and New Zealand with national efforts to provide the public with documents that are easier to understand, efforts involving research on plain English and document design (e.g., The Tax Law Improvement Project of the Federal Inland Revenue Department). McLaren further cites a seminal study on the public role of communication scholars. Noting the role of business communication research in Canadian public policy, Sutcliffe describes government funding for "applied research projects that can be used by government and industry groups seeking input for social and economic policy formation." She further contends that the challenge for researchers is "to understand business communication as a nation-building activity and as an activity that can potentially transform the nation."

Nakasako and Sutcliffe also associate cultural studies in our field with national objectives. Nakasako describes Japanese business communication efforts as inclined toward attaining the highest levels of success in the global economy through "a deep understanding of the cultures of all the parties involved." Using this cultural knowledge, he suggests, should allow Japanese to subordinate their cultural inclinations in order to succeed in international negotiations. By contrast, Sutcliffe speaks of "Canada's cultural identity crisis" and asks for more studies that look at Canada as a "unique culture, worthy of the same attention we give to understanding business communication in Japan, Germany, and the US." In fact, she applauds Graves's efforts to discern "what may be uniquely Canadian about Canada's business communication." 
The fact that business communication research activities are tied to national agendas raises a number of questions for us as an association of researchers and teachers:

- How is business communication research supported and influenced by national political interests in various regions? To what extent do such interests enable and constrain research?

- Should researchers intensify efforts to obtain research support from national and international organizations?

- How do national interests impact international research collaborations?

- Does nationalism color the teaching of business communication? Are national concerns impeding efforts to help students understand what it means to conduct business from a global perspective?

\section{The English Divide}

These authors' descriptions also suggest that we share a keen interest in English as an international business language, but that we teach and study it from quite different perspectives. On the one hand, as YliJokipii and Charles explain, business communication involves the study of language and the discourse of business events; along similar lines, Nakasako describes English as the language of trade. Then, too, English is the language by which we associate internationally: it is the language of $A B C$ and the primary language for research publications worldwide (Ahmad, 1997). On the other hand, English also divides us. As a community of scholar-teachers, we understand English from two very different vantage points: Some of us possess English as a mother tongue; others do not. And this difference matters, I believe. Exactly how it matters is hinted at in the opening statement of Charles's article:

Research on oral business communication in Europe is deeply rooted in the multicultural and multilingual reality of the continent. Most European business people (with the possible exception of the British) must use at least one foreign language to do business.

In separating "the British," Charles implies that the "multilingual reality" that is part and parcel of business transactions in most of Europe is less so in English-speaking Britain. So, too, multilingualism, English as a Second Language (ESL), and Business English (BE) dominate the 
articles on business communication activities in Europe, Japan, and Malaysia, but not the articles on activities in English-speaking countries, as shown in McLaren's piece about Australia and New Zealand (which does have one paragraph on the Maori). Even Sutcliffe writes from the perspective of English-based Canada, although the situation would be different, one expects, in Quebec.

Evidence that this English divide has some real implications for our international business communication community became apparent during a session at the 1997 International ABC Convention. Presented by Ayseli Usluata and titled "Using English as the Medium of Instruction in the Business Communication Class in Turkey," the session revealed that students at Bogazici University in Istanbul resented the need to subordinate their own language to learn English for business purposes. Other non-native English speakers at the session identified with Usluata's observation. Taking objection, a native English speaker in attendance commented that she was the ultimate loser, having been "robbed" of her mother tongue as well as the pressing need to become bilingual herself. These two reactions to English are not unique: Consider Louhiala-Salminen's discovery that employees at a Finnish export company regarded English as "just a code I use" and a "cultureless" language (1997, p. 317) and consider the implicit resentment in the claim that "the English language...is strengthening its dominating grip" (Ahmad, 1997, p.6). These perspectives suggest that, although we study English all the time, we have yet to consider how our different perspectives on it may be influencing our own work as well as how we interpret the work of others.

- Is miscommunication taking place between native and non-native speakers of English doing business communication research worldwide and, if so, what is the impact on our research and its interpretation?

- Given the importance of English for international business transactions and the attention it receives in business communication teaching and research, what difference does it make that some of us understand English as a second language while for others it is the "mother tongue"? How is either perspective advantaged and disadvantaged?

- Relative to other languages, what is the contribution of English to global business communications? 
Of course, this issue is further complicated when we consider that many Englishes are operating within our research community, each deeply rooted in our individual cultural realities and each involving unique linguistic effects. International colleagues, especially those who speak English as a second (or third, or fourth ...) language, are helping us to place such issues on the research agenda. Moreover, which English to teach and in what way remain questions for pedagogical researchers worldwide. As Nakasako and Tan comment, some programs are moving away from the ESL and BE approaches, while others, as Charles notes, continue to link business communication with ESL and BE.

Relatedly, it could prove informative to compare research and teaching efforts in European countries, where the focus is on contrastive language studies (see Charles and Yli-Jokipii), with Japan's seemingly singular quest for proficiency in the "English of trade." Or to compare views on English in the US with those in Singapore, where English has in some respects become the native tongue. (As a Chinese Singaporean banker recently reminded me, "My mother tongue is English not Cantonese!")

\section{Next Steps}

These articles suggest that business communication researchers worldwide comprise an identifiable group of loosely connected individuals who share common views of the field. Collaborative endeavors are also evident: McLaren, for example, relays how "communication-needs analyses" conducted in US accounting firms were subsequently conducted in New Zealand; Charles describes a multifaceted European-American project involving "shadowing" managers in England, Finland, Sweden, and the United States. In fact, ABC itself has become a kind of academic United Nations-a working body with international members who retain autonomy while seeking mutual understanding, cooperation, and support to advance business communication research and teaching. To shift the analogy, however, we may need to work toward a more integrated global community of scholarteachers. An integrated body would probably look more like the emerging European Union than the UN. Building such a body would require more willful, organized efforts to identify and reduce barriers inhibiting the trade of ideas, much as our $\mathrm{ABC}$ home page and Web- 
sites, conference roundtables, and think tanks have done. Even more, it would require continuing efforts toward developing a kind of common currency for global knowledge production and exchange, improving our distribution systems and networks to disseminate research and pedagogical materials, as well as reaching some consensus regarding our communal goals and global standards for membership. And, I believe, it would require coming to terms with issues such as our differing national commitments and our divided perspective on English.

\section{References}

Ahmad, U. K. (1997). Scientific Research Articles in Malay: A Situated Discourse

Analvsis. Ph. D. dissertation, University of Michigan.

Andrews, D. C. (1988). Technical Communication in the Global Community. Upper Saddle River, NJ: Prentice Hall.

Graves, R. (1997). 'Dear Friend' (?): Culture and genre in American and Canadian direct marketing letters. The Journal of Business Communication, 34 (3), 235-252. Hagen, P. (1998). Teaching American business writing in Russia: Cross-

cultures/cross-purposes. Journal of Business and Technical Communication, 12 (1), $109-126$.

Locker, K. O. (1998). The role of The Association for Business Communication in shaping business communication as an academic discipline. The Journal of Business Communication, 35 ( 1 ), 14-49.

Louhiala-Salminen, L. (July 1997). Investigating the genre of a business fax: A Finnish case study. The Journal of Business Communication 34 (3), 316-333.

\section{Europe: Oral Business Communication}

\section{Mirjaliisa Charles}

Helsinki School of Economics and Business Administration. Finland

RESEARCH on oral business communication in Europe is deeply rooted in the multicultural and multilingual reality of the continent. Most European businesspeople (with the possible exception of the British) must use at least one foreign language to do business. For most, that foreign language is English - with French and German having clear significance. It is no surprise, therefore, that European business communication research is closely linked with the needs of foreign language learning and teaching. Indeed, instead of speaking about business communication, researchers, teachers, and trainers fre- 